\title{
Two thousand years of boreal biomass burning recorded in the NEEM ice cores
}

\author{
Natalie Kehrwald', P. Zennaro1,2, S. Schüpbach³, T. Kirchgeorg', J. R. McConnell', R. Zangrando², A. Gambaro',
} and C. Barbante $1,2,5$

\begin{abstract}
New data from Greenland ice cores reveal a major peak in boreal biomass burning during the 1600 s AD, presumably related to major regional droughts in Central Asia. This climate-related peak in fire activity is greater even than postindustrial biomass burning.
\end{abstract}

\begin{abstract}
Fires ignited by humans to manage the landscape may have started altering atmospheric greenhouse gas concentrations and warming the planet thousands of years ago (Ruddiman 2003). Today, biomass burning produces up to $50 \%$ as much carbon dioxide as fossil fuel burning (Bowman et al., 2009) while at the same time shrinking an important carbon sink.

Polar ice cores present a unique medium to quantitatively investigate past biomass burning at the global scale because they trap and archive fire-related aerosols before and after humans began influencing the global carbon cycle.
\end{abstract}

Here, we synthesize information from three geochemical fire activity proxies, i.e. levoglucosan, black carbon, and ammonium measured in the NEEM and NEEM-2011-S1 ice cores from Greenland (Fig. 1) to investigate interactions between Northern Hemisphere fire activity, climate, and possible human influences in boreal regions over the last 2000 years.

\section{Fire proxies in ice cores}

Several tracers of past biomass burning can be measured in polar ice cores. Aerosols are transported in smoke plumes from Eurasia and North America over thousands of kilometers. Some of the aerosols are transported all the way to Greenland, deposited there and trapped within the ice sheet (Kehrwald et al. 2012; Zennaro et al. 2014). Ammonium is a tracer of biomass burning, especially in boreal regions (e.g. Legrand et al. 1992), but also enters the atmosphere through interactions with fertilizers, manure, and marine sources. Black carbon is a more specific proxy as it is produced by the incomplete combustion of both biomass and fossil fuels (McConnell et al. 2007). Both black carbon and ammonium can be determined using high-resolution continuous flow analysis techniques (CFA; Zennaro et al. 2014). Fire information is also inferred from the isotopic composition of methane $\left(\mathrm{CH}_{4}\right)$. The $\delta^{13} \mathrm{C}$ of $\mathrm{CH}_{4}$ is enriched if it was produced by a pyrogenic process compared to biogenic sources including rice cultivation, ruminants or wetlands (Sapart et al., 2012) Note, however, that due to methane's atmospheric lifetime of several decades, the ${ }^{13} \mathrm{C}$ of $\mathrm{CH}_{4}$ is a global mixture from sources with different isotopic signatures (Sapart et al. 2012). Finally, levoglucosan, a monosaccharide anhydride, has strong potential for tracing broad-scale fire activity. It is only produced by burning cellulose at temperatures of $300^{\circ} \mathrm{C}$ or higher (Simoneit 2002) and represents one of the principal constituents of smoke plumes. Levoglucosan is currently only determined in discrete samples, resulting in lower-resolution records than parameters analyzed by CFA techniques.

Our study acknowledges both the strength and the weaknesses inherent in most ice core fire proxies and remedies the latter

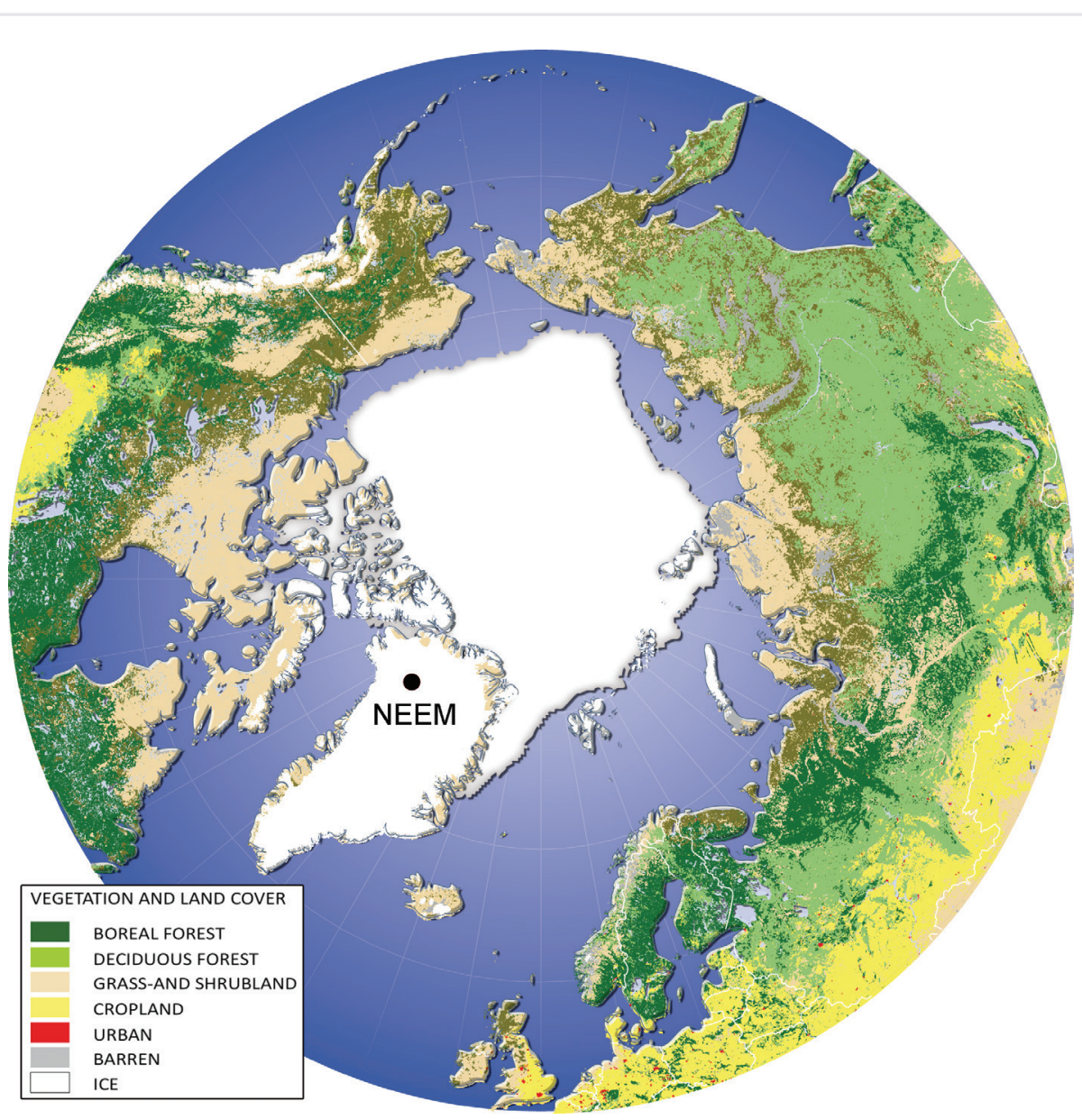

Figure 1: Distribution of the high northern latitude land cover and location of the NEEM ice core drilling site at $77.49^{\circ} \mathrm{N}, 51.2^{\circ} \mathrm{W}, 2480 \mathrm{~m}$ above sea level. Modified from the European Commission Global Land Cover 2000 database and based on the work of cartographer Hugo Alhenius UNEP/GRIP-Arendal. 
by integrating the results from ammonium, black carbon, and levoglucosan records from the NEEM ice cores over the past 2000 years (Zennaro et al. 2014).

\section{Boreal biomass burning and climate}

Fires are individual events lasting hours to weeks, yet droughts, increased temperatures, or land use changes can increase net fire activity over years to centuries. We compare our records with other biomass burning and climate reconstitutions from elsewhere to locate the geographical extent of the fire activity reconstructed from the NEEM ice cores and to investigate their driving factors. To all of the records we applied a locally-weighted scatterplot smoothing (LOWESS, details on the statistical method in Zennaro et al. 2014) and normalized all data as z-scores to ease the comparison between the different records (Fig. 2).

The NEEM levoglucosan record peaks over a century-long period, centered on 1640 AD (Fig. 2). Although less prominent, high values around that time also exist in the NEEM black carbon records (Fig. 2). A regional average record of northern high latitude $\left(>55^{\circ} \mathrm{N}\right)$ charcoal data from the Global Charcoal Database of the Global Palaeofire Working Group (www.gpwg.org) shows similar trends to the levoglucosan record throughout most of the last two thousand years, with the interesting exception of low charcoal values during the $1640 \mathrm{AD}$ levoglucosan peak (Fig. 2). However, the majority of the boreal charcoal data are located in North America, thus geographically weighting the resulting synopsis. This could explain the observed difference between the levoglucosan and hemispheric charcoal record syntheses during this time period.

Tree-ring, speleothem, and alpine ice core data (e.g. from the Belukha ice core in Mongolia) demonstrate widespread, decadal-scale droughts over most of Central Asia coincident with major fire peaks in the NEEM ice core (Zennaro et al. 2014). These Central Asian droughts, and associated fire activity peaks, do not correspond with either increased regional or Northern Hemisphere land temperatures (Fig. 2). Therefore, over decadal timescales, we propose that precipitation changes may be an important fire-controlling factor. Except during the 1640 AD fire peak, the resemblance observed between the NEEM levoglucosan, black carbon, and Northern Hemisphere temperature reconstructions suggests that temperature might be the major control of boreal biomass burning over centennial timescales.

\section{Conclusions}

Our multi-proxy (levoglucosan, black carbon, and ammonium) reconstruction of fire activity based on the NEEM ice cores suggests that temperature was the main control on boreal fire activity over the past two thousand years, while major droughts influenced biomass burning over decadal timescales. Our dataset suggests a peak
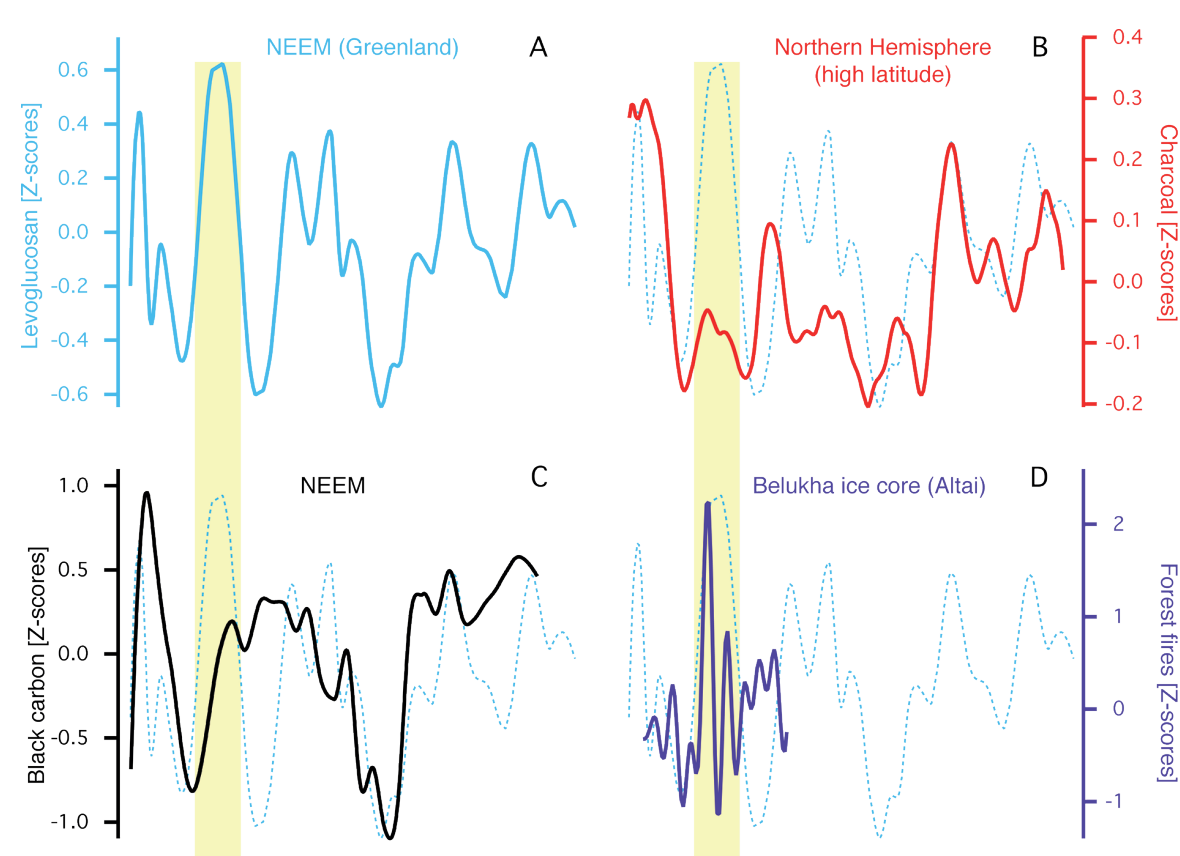

C
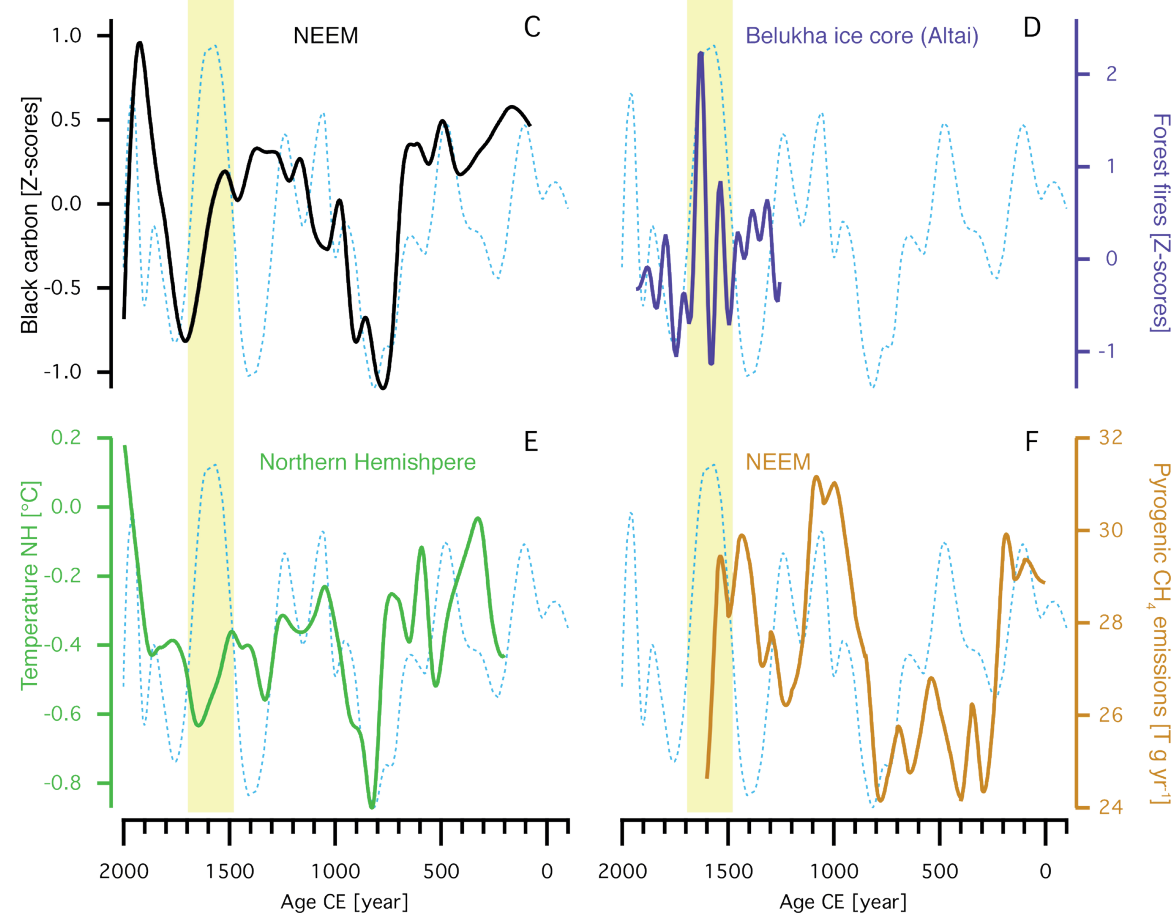

Figure 2: Climatic and environmental records over the past 2000 years, presented as z-scores smoothed by incorporating the nearest $10 \%$ of data. (A) NEEM levoglucosan concentrations; (B) Boreal charcoal concentrations (Marlon et al. 2008); (C) NEEM black carbon versus levoglucosan concentrations; (D) Siberian forest fire reconstruction (Eichler et al. 2011); (E) Northern Hemisphere land temperature (Mann et al. 2008); (F) NEEM pyrogenic $\mathrm{CH}_{4}$ emissions (Sapart et al. 2012). Dashed blue lines in panels B-F are the levoglucosan record from $A$ for reference. The yellow vertical bar marks the levoglucosan-based $17^{\text {th }}$ century fire activity maximum highlighted in the text.

in fire activity in the mid-1600s, which coincides with the most severe Central Asian droughts of the past two millennia. This fire activity peak is higher than any biomass burning recorded at NEEM after the Industrial Revolution, when land-clearing rates were the highest in recorded history. Therefore, this dominance of the 1640 AD fire peak suggests that climate affected boreal biomass burning more than human activity over the past two thousand years.

\section{ACKNOWLEDGEMENTS}

The research leading to these results received funding from the European Union's Seventh Framework programme (FP7/2007-2013) under grant agreement no. 243908 , grant agreement no. 267696 , and the U.S. National Science Foundation award no. 0909541

\section{AFFILIATIONS}

${ }^{1}$ Department of Environmental Science, Informatics and Statistics, Cà Foscari University of Venice, Italy ${ }^{2}$ IDPA-CNR, Venice, Italy

${ }^{3} \mathrm{Climate}$ and Environmental Physics, Physics Institute and Oeschger Centre for Climate Change Research, University of Bern, Switzerland

${ }^{4}$ Desert Research Institute, Department of Hydrologic Sciences, Reno, USA
${ }^{5}$ Centro B. Segre, Accademia Nazionale dei Lincei, Rome, Italy

\section{CONTACT}

Natalie Kehrwald: Kehrwald@unive.it

\section{REFERENCES}

Bowman et al. (2009) Science 324: 481-484 Eichler A et al. (2011) Quat Sci Rev 30: 1027-1034 Holmes BJ, Petrucci GA (2007) J Atmos Chem 58: 151-166 Kehrwald N et al. (2012) Tellus B 64: 18196 Kirchgeorg T et al. (2014) Org Geochem 71: 1-6 Legrand M et al. (1992) Geophys Res Lett 19: 473-475 Mann et al. (2008) PNAS 105: 13252-13257 Marlon et al. (2008) Nat Geosci 1: 697-702

McConnell JR et al. (2007) Science 317: 1381-1384 Ruddiman WF (2003) Clim Change 61: 261-293 Sapart C et al. (2012) Nature 490: 85-88 Savarino J, Legrand M (1998) J Geophys Res Atmos 103: 8267-8279

Simoneit BRT (2002) Appl Geochem 17: 129-162 Zennaro P et al. (2014) Clim Past 10: 1905-1924 